\title{
External Costs of Transporting Petroleum Products: Evidence from Shipments of Crude Oil from North Dakota by Pipelines and Rail
}

\author{
Karen Clay, * Akshaya Jha, ** Nicholas Muller,*** and Randall Walsh****
}

\begin{abstract}
Using data for crude oil transported out of North Dakota in 2014, this paper constructs new estimates of the air pollution, greenhouse gas, and spill and accident costs from long-distance movement of petroleum products by rail and pipelines. Our analysis has three main findings. First, air pollution and greenhouse gas costs are nearly twice as large for rail as for pipelines. Second, air pollution and greenhouse gas costs are much larger than estimates of spill and accidents costs. Third, air pollution and greenhouse gas costs of transporting fuel by rail and pipelines are one-fifth to one-tenth of the costs of combusting fuel in motor vehicles. These results suggest that the policy debate surrounding crude oil transportation may be putting too much relative weight on spills and accidents, while overlooking a far more serious external cost: air pollution and greenhouse gas emissions.
\end{abstract}

Keywords: Crude oil, Air pollution, Greenhouse gases, Railroads, Pipelines

https://doi.org/10.5547/01956574.40.1.kcla

\section{INTRODUCTION}

This paper constructs new estimates of the air pollution, greenhouse gas, and spill and accident costs associated with the long-distance movement of petroleum products by rail and pipelines. Movements of petroleum products, particularly crude oil, have received enormous media attention. Almost all of the attention, including very recent coverage (Smith, 2017), has focused on spill and accident costs despite the fact that air pollution and greenhouse gas costs are also likely to be significant.

Pollution emissions for pipelines and rail differ from one another in three important ways. First, while emissions from trains occur along the transportation route, emissions from pipelines manifest at the power plants that generate the electricity consumed by pumping stations. The distance between these power plants and the associated pumping stations can be quite large. Second, ground-level emissions, such as those from locomotives, tend to be more harmful than the same level of emissions released from tall smokestacks at power stations (Muller and Mendelsohn, 2009).

* Corresponding author. Professor of Economics and Public Policy, Carnegie Mellon University and NBER, Heinz College, 5000 Forbes Avenue, Pittsburgh, PA 15213. Phone: 412-268-4197. E-mail: kclay@andrew.cmu.edu.

** Assistant Professor of Economics and Public Policy, Carnegie Mellon University, Heinz College, 5000 Forbes Avenue, Pittsburgh, PA 15213. Phone: 608-347-2102. E-mail: akshayaj@andrew.cmu.edu.

*** Lester and Judith Lave Associate Professor of Economics, Engineering, and Public Policy, Tepper School of Business, Department of Engineering and Public Policy, Carnegie Mellon University, 5000 Forbes Avenue, Pittsburgh, PA 15213. Phone: 412-268-8121. E-mail: nmz@andrew.cmu.edu.

**** Professor of Economics, Department of Economics, 4511 WW Posvar Hall, 230 S. Bouquet St., Pittsburgh, PA 15260. Phone: 412 648-1737. E-mail: walshr@pitt.edu. 
Third, the existing railroad infrastructure moves goods through population centers. In contrast, power plants are typically located in less densely-populated areas. This final difference matters for pollution exposure, because the emissions from trains moving through cities are likely to affect many more people than those emitted at power plants.

To construct our estimates, we use data on locomotive diesel consumption, pipeline pumping station electricity consumption, locomotive and power plant emission factors, and the AP3 integrated assessment model, which maps county level emissions to costs for counties affected by the emissions. Estimates are constructed for movements of crude oil from North Dakota in 2014, a year in which roughly half of said crude oil was shipped to refineries by rail and half was shipped by pipelines. Locomotive diesel consumption is estimated based on movements of crude oil from the Surface Transportation Board's Confidential Waybill Sample and industry data on average tonmiles per gallon. Our approach to estimating diesel consumption is similar to that taken by U.S. Department of State (2014). Pipeline pumping station electricity data is from Genscape (2014). The AP3 integrated assessment model estimates changes in county-level air pollution based on changes in emissions. To construct estimates of county-level damages, the AP3 model uses census data on population and other county characteristics together with peer-reviewed concentration-response functions and valuations of outcomes used by the EPA. We construct estimates of spill and accident costs from Pipeline and Hazardous Material Safety Administration (PHMSA) regulatory impact analyses. ${ }^{1}$

Our analysis has three main findings. First, air pollution and greenhouse gas costs are substantially larger for rail than for pipelines. For shipments of crude oil from North Dakota to the Gulf Coast in 2014, the air pollution and greenhouse gas costs are nearly twice as large for rail as for pipelines. ${ }^{2}$ We provide evidence that the higher air pollution and greenhouse gas costs for rail relative to pipelines generalize to other products, routes, and years in North America. Second, air pollution and greenhouse gas costs are three times as big as spill and accident costs for rail and ten times as big for pipelines. Thus, the policy debate surrounding crude oil transportation has likely put too much relative weight on accidents and spills, while overlooking air pollution and greenhouse gas emissions, which appear to be a far more serious source of external cost. Third, the air pollution and greenhouse gas costs of rail transportation of crude are about one-fifth of the air pollution and greenhouse gas costs from combusting their refined end-products in motor vehicles and about onefifth the private cost to the shipper of rail transport. The costs for pipelines are one-tenth the costs of combusting fuel in motor vehicles and one-fifth of the private costs of shipping crude oil.

This paper contributes to the literature on transportation of crude oil. In particular, it complements work by Covert and Kellogg (2017) on the flexibility of crude by rail and the effect of rail prices on optimal pipeline capacity investment. They calculate that if rail had to internalize pollution externalities of $\$ 2$ per barrel, which is roughly the estimated value in this paper, the capacity of the Dakota Access Pipeline would have been 59,000 barrels per day above its current level of 470,000 barrels per day. Similarly, we connect to work on the broader impacts of increased shipments of crude by rail such as that by Bushnell et al (2017) which examines the effects of heightened crude oil traffic on wheat, corn, and soy prices in North Dakota and nearby states.

This paper also contributes to the broader literature on air pollution associated with transportation. For a summary, see NRC (2009) on combustion costs. Estimates of air pollution and

1. Data limitations prevent us from considering other external costs such as noise and vibration and from considering historical or contemporary subsidies to rail or pipelines.

2. We cannot make similar comparisons for the East Coast and West Coast, because crude oil pipeline capacity to these locations is negligible. 


\section{Figure 1: U.S. Originated Weekly Rail Traffic for Petroleum and Petroleum Products}

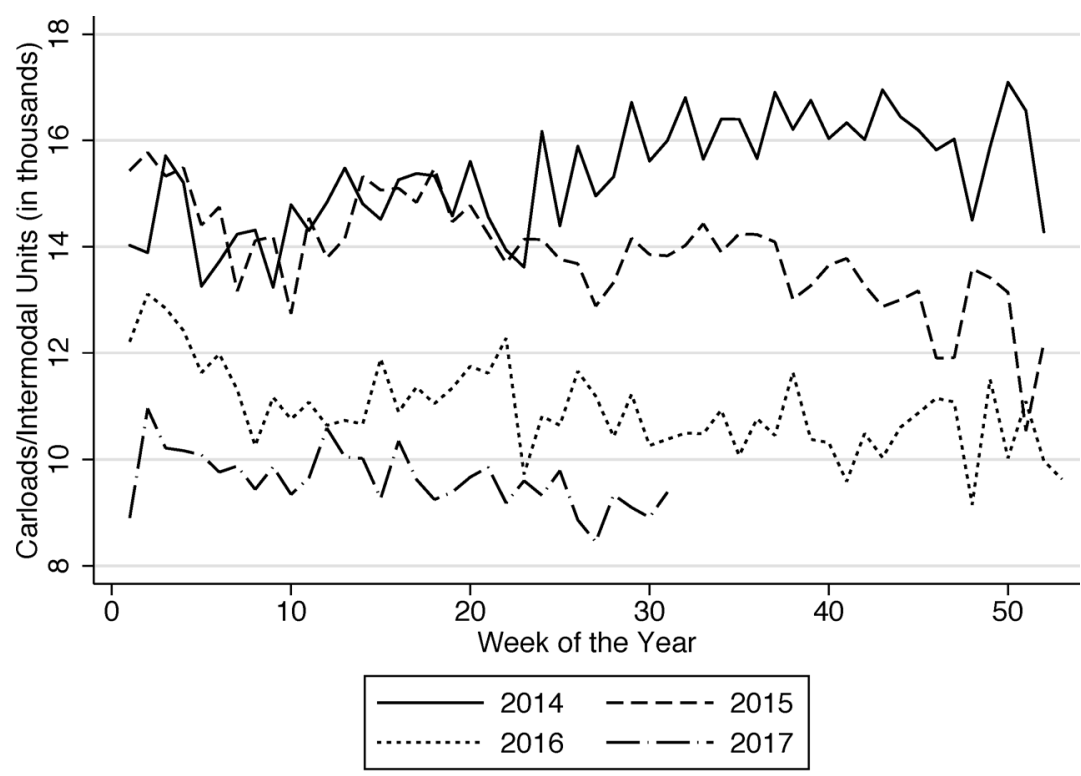

Notes: U.S. Originated Weekly Rail Traffic for Petroleum and Petroleum Products are from Association of American Railroads: https://www.aar.org/data-center/rail-traffic-data

greenhouse gas damages from rail transport are largely absent from the recent literature. For example, perhaps the most recent estimates for rail are those of Forkenbrock (2001) which were derived from cost per ton estimates by Haling and Cohen (1995), which are in turn based on estimates from a 1993 study by National Economic Research Associates (NERA) that looked at electric utility resource selection in Nevada.

\section{BACKGROUND}

Figure 2 shows that oil production in the United States increased tremendously beginning in 2008. One driving factor was the rise of production in the Bakken Field, which is primarily located in North Dakota. As a result of this rapid increase in production, in 2014 North Dakota was the third largest producer of oil in the United States after Texas and the federal offshore region in the Gulf Coast.

Shippers send oil to the location that provides them with the largest revenue net of transportation cost (termed "netbacks"). Firms move oil to a rail or pipeline terminal using either truck or gathering pipelines. ${ }^{3}$ Our analysis focuses on the long distance transportation of crude oil and excludes these 'first miles' primarily because of difficulties in obtaining detailed data on how oil was moved from the wellhead to a terminal. ${ }^{4}$ Firms can ship crude oil to refineries using a range of

3. In aggregate, about 50 percent of oil was shipped from the wellhead by a gathering pipeline (North Dakota Pipeline Authority 2015).

4. We have not been able to determine the extent to which trucking is correlated with moving crude oil by rail versus pipeline. If trucking for the "first mile" is positively correlated with subsequently moving crude oil by rail, this will increase the air pollution associated with rail. If trucking and crude-by-rail are negatively correlated, this will increase the air pollution from crude-by-pipeline. The Director of the North Dakota pipeline authority did not know whether the correlation was negative or positive [private correspondence]. 
Figure 2: Crude Oil Production in the United States and North Dakota

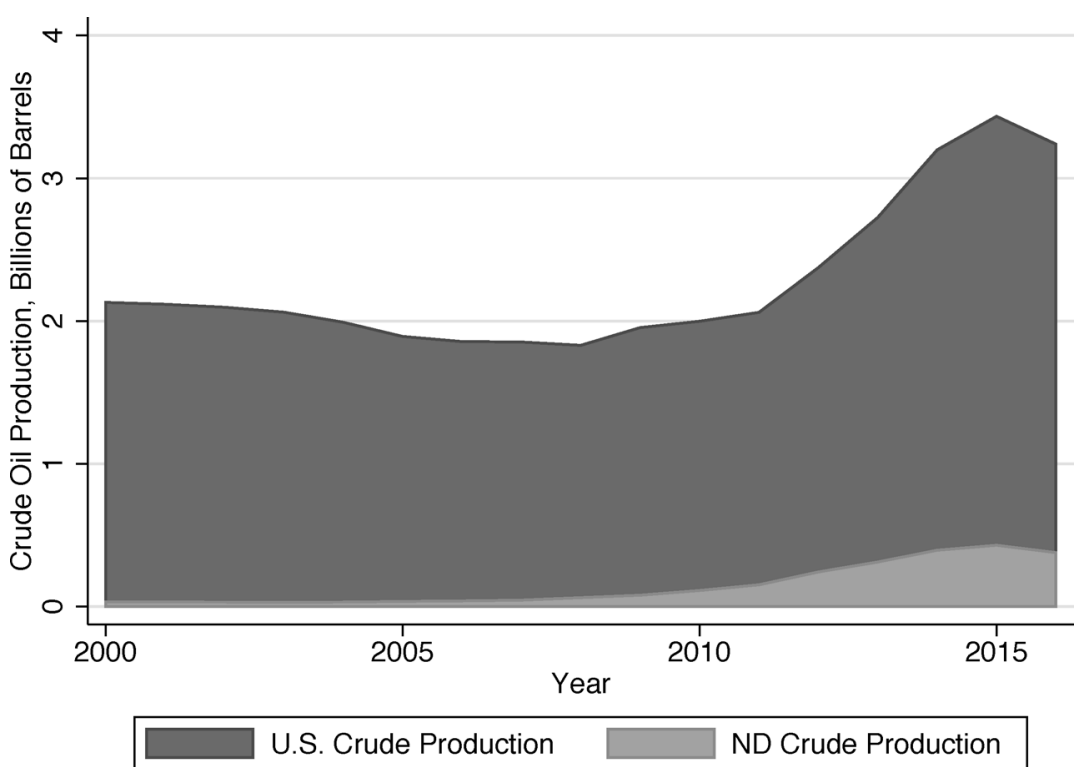

Notes: United States and North Dakota crude oil production are from Energy Information Administration (nd). Crude Oil Production, Annual.

modes of transportation, including rail, pipeline, or some combination of rail, pipeline and water. In this last case, oil is initially transported by rail or pipeline and is then offloaded to tankers or barges for shipment to refineries. In 2014, U.S. refineries reported receiving 78 percent of domestically produced crude oil by rail or pipeline. ${ }^{5}$ They reported receiving the remaining 22 percent by tanker, barge, or truck.

Firms shipping crude oil from the Bakken are likely to use pipelines to the extent that there is available capacity, because rail is significantly costlier than pipeline per barrel-mile shipped. For example, Frittelli et al $(2014$, p. 7$)$ noted that: "Railroad transport reportedly costs in the neighborhood of $\$ 10$ to $\$ 15$ per barrel compared with $\$ 5$ per barrel for pipeline." This is consistent with information from Genscape's Petrorail Report (various dates) and with the prices reported in Covert and Kellogg (2017). Additional oil is shipped by rail to the extent that it is economically attractive to do so. Rail offers some benefits over pipelines, because it serves a more flexible set of destinations with faster delivery times. Another factor in the continued use of rail- even when the economics appear unfavorable - is the fact that some shippers entered into multi-year contracts for rail shipments when the price of oil was high. These "take-or-pay" contracts require them to ship oil by railroad or pay for unused capacity.

Roughly half of the oil shipped from North Dakota in 2014 went by pipeline to refineries and the vast majority of oil traveling by pipeline went to refineries on the Gulf Coast. Most of the oil moving by pipeline ends up in the Gulf Coast, because there is almost no crude oil pipeline in-

5. Authors' calculation based on Energy Information Administration (nd) data on Refinery Receipts of Crude Oil by Method of Transportation for 2014. 
frastructure on the East and West Coasts. ${ }^{6,7}$ The other half of the oil shipped from North Dakota in 2014 went to refineries by rail, with the largest share going to the East Coast. ${ }^{8}$

At refineries, the increased availability and favorable pricing of domestic oil led to reduced use of foreign oil. For example, in the U.S. between 2011 and 2014, domestic crude oil received at refineries increased by about 1 billion barrels and foreign oil decreased by about 500 million barrels. In total, crude oil consumption by refineries increased by about 9 percent.

A central issue in North Dakota is the extent to which trains carrying crude oil crowd out the rail transportation of other products. When evaluating the air pollution effects of crowding out, it is helpful to think about the two ends of the spectrum. The first extreme is that railroads are operating with excess capacity and so additional rail traffic has no congestion externality on the rail system. In this case, any additional crude-by-rail traffic increases the overall air pollution costs from transporting goods by rail. The other end of the spectrum is that railroads are already operating at full capacity. In this case, increased crude-by-rail traffic completely crowds out lower value products. There is no change in the total rail traffic due to crude-by-rail in this scenario, and thus there is no change in the overall air pollution costs from transporting goods by rail. In fact, the crowding out of other products may cause additional pollution, if these products are transported by other higher pollution modes such as trucks instead. Thus, there are three possible sources of air pollution: i) railroad-related pollution from increases in rail traffic; ii) any additional pollution related to system-wide railroad congestion, since slower speeds are associated with higher fuel consumption; and iii) pollution stemming from products being shipped by other, more environmentally harmful modes of transportation (such as truck) rather than by rail.

North Dakota is heavily reliant on rail to move agricultural goods $-80 \%$ of grain was transported by rail between 2009 and 2012. Agricultural goods such as grain may be "time-shifted" rather than crowded out. Namely, higher tariff traffic such as crude oil may be moved first; other lower tariff traffic such as agriculture may be moved as capacity emerges. Rail capacity concerns materialized in 2013/14. The problem was particularly acute because of the record corn, soybean, and wheat harvests in that year.

If crude-by-rail crowded out the rail transportation of other goods, we would expect to see declines in agricultural shipments. Figure 3 shows the monthly total number of carloads originating in North Dakota, separately for oil, coal, and agricultural products. We removed seasonal trends in this figure by subtracting the month-of-the-year average total carloads of each good from the monthly observations. We smoothed the resulting de-trended carloads' time series using the LOW-

6. Of the 266 million barrels moved by pipeline from the Midwest (Petroleum Administration for Defense District 2, or PADD2), which includes North Dakota, 1 percent moved to the East Coast (PADD1), 84 percent moved to the Gulf Coast (PADD3) and 15 percent to the Rocky Mountains (PADD4). The United States was divided into five Petroleum Administration for Defense Districts during World War II. These districts are still used for administrative purposes today. For a map showing the location of the five Petroleum Administration for Defense Districts, see https://www.eia.gov/petroleum/marketing/monthly/pdf/paddmap.pdf.

7. In addition, roughly 67 million barrels stayed within the Midwest (PADD2). Energy Information Administration (nd) data on Movements of Crude Oil and Selected Products by Rail. It is possible to back out approximate movements of oil by pipeline within the Midwest (PADD2) by taking total production in PADD2 and subtracting movements to other PADDs by all modes. Further, crude by rail is tracked within PADD2, so the residual is predominantly pipeline with some small share of water movement. Summarizing, our approximation (in thousand barrels) of the pipeline movements within PADD2 is calculated as follows: $67,000=616,000$ (production) $-539,000$ (shipments out of PADD2)-10,000 (crude by rail movements within PADD2).

8. Of the 250 million barrels moved by rail from the Midwest in 2014, 54 percent moved to the East Coast, 21 percent moved to the Gulf Coast, 21 percent moved to the West Coast, and 4 percent moved to the Rocky Mountains. 


\section{Figure 3: Smoothed and Detrended Monthly Rail Carloads of Oil, Coal and Agriculture Originating in North Dakota}

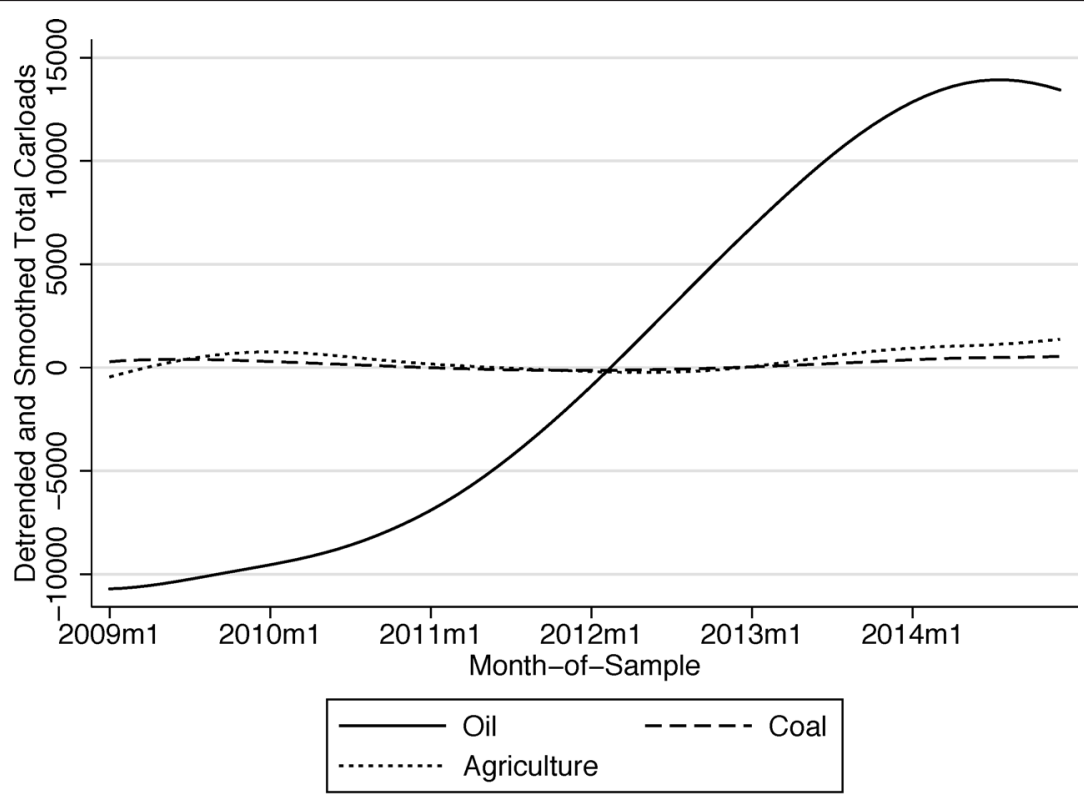

Notes: Based on STB Confidential Waybill Sample. Seasonal trends were removed by subtracting the month-of-the-year average total carloads of each good from the monthly observations. The resulting de-trended carloads' time series was smoothed using the LOWESS method.

ESS method. ${ }^{9}$ This figure demonstrates that the (de-trended, smoothed) total number of carloads of crude oil shipped by rail from North Dakota markedly increased over time. Consistent with railroads having excess capacity, we do not see a corresponding decrease in the number of carloads of coal or agricultural goods shipped. ${ }^{10}$ As USDA (2015) noted, despite producers' complaints exports of agricultural products also increased over this period.

Based on this evidence, we assume in our analysis that railroads are operating with excess capacity. In total, we are estimating a lower bound on the air pollution associated with transporting crude oil following the Bakken oil production boom, because: 1) emissions per ton-mile for alternative forms of transportation (such as trucks) are higher than for railroads, 2) we are ignoring rail congestion effects, 3 ) as we will discuss further in section 3, our main estimates do not include idling, and 4) we ignore emissions associated with transport from wellheads to on-loading terminals.

\section{DATA}

Our rail analysis draws on confidential waybill data for 2014 from the Surface Transportation Board (STB). These data are a stratified sample of all waybills. ${ }^{11}$ The STB data include information on the class of goods being carried, origin county, destination county, major intermediate

9. LOWESS stands for Locally Weighted Scatterplot Smoothing and is useful for showing a smooth line through a scatterplot.

10. Bushnell et al (2017, p. 4) find that "shippers in western North Dakota and Montana are more likely to ship wheat to West Coast destinations."

11. Waybills corresponding to a higher number of carloads are sampled at a higher rate. More detail on the STB's sampling procedure is available from the STB's website 
Table 1a: Summary Statistics for Movements of Crude Oil by Rail

\begin{tabular}{lccc}
\hline Destination & Number of Routes & $\begin{array}{c}\text { Average Length Of Route } \\
\text { (Miles) }\end{array}$ & $\begin{array}{c}\text { Total Barrels Shipped } \\
\text { (million BBL) }\end{array}$ \\
\hline All Observed Waybills & $41^{\mathrm{B}}$ & $1,673.40(388.18)$ & $204.0^{\mathrm{C}}$ \\
Gulf Coast & 10 & $1,905.81(301.21)$ & 53.7 \\
East Coast & 16 & $1,910.16(123.62)$ & 91.6 \\
West Coast & 9 & $1,360.21(290.22)$ & 41.6 \\
\hline
\end{tabular}

Notes: Movement of crude oil from North Dakota in 2014. A = Standard Deviations in parentheses. B = The number of routes from East Coast + Gulf Coast + West Coast does not equal 41 because some routes end either in the Midwest or Ontario. C $=$ The total barrels for all waybills exceeds the sum across Gulf Coast, East Coast, and West Coast because some routes end either in the Midwest or Ontario.

Table 1b: Summary Statistics for Movements of Crude Oil by Pipeline

\begin{tabular}{lcccc}
\hline & $\begin{array}{c}\text { Distance between } \\
\text { pumping stations } \\
\text { NERC Region }\end{array}$ & $\begin{array}{c}\text { Power Consumption } \\
\text { (megawatt hours/yr.) }\end{array}$ & $\begin{array}{c}\text { Oil Flow } \\
\text { (million barrels/yr.) }\end{array}$ & $\begin{array}{c}\text { Number of } \\
\text { Monitors }\end{array}$ \\
\hline MRO & 160.04 & $68,237.9$ & 142.2 & 65 \\
RFC & 277.14 & $23,726.0$ & 104.9 & 32 \\
SERC & 109.33 & $23,785.1$ & 77.0 & 83 \\
SPP & 130.58 & $21,793.6$ & 55.9 & 126 \\
TRE & 75.97 & $31,560.1$ & 104.7 & 41 \\
WECC & 111.31 & $50,609.3$ & 92.0 & 57 \\
All & 134.94 & $34,885.0$ & 88.0 & 404 \\
\hline
\end{tabular}

Notes: Crude oil pipeline data for 2014 from Genscape (2014).

interchange points (such as Chicago, East St. Louis, and Detroit), rail carrier, tons shipped, and number of carloads. ${ }^{12}$

Data on the location of rail networks used to transport crude oil across the United States are from the Center for Transportation Analysis at Oak Ridge. ${ }^{13}$ Using GIS, we measured the number of miles of track in each county for all rail routes carrying high volumes of crude oil from North Dakota. Because many lines run along county boundaries, we computed a one-mile wide buffer along each line and used the relative areas to allocate rail miles to counties.

Table 1a shows routes, route lengths, and barrels shipped across all waybills and by region. In 2014, trains transported roughly 214 million barrels of crude oil produced in North Dakota. We map and analyze over 95 percent of this crude-by-rail traffic over 41 distinct routes from North Dakota to refineries across the contiguous U.S.

Our pipeline analysis draws on data from Genscape on monthly movement of crude oil by pipeline from the Bakken. In 2014, their data covered 68 percent of crude oil transported by pipeline from North Dakota. Genscape (2014) also provided us with data on monthly electricity consumption at selected pumping stations for these pipelines and GIS information on pipelines and pumping stations.

Table $1 \mathrm{~b}$ shows distance between pumping stations, pumping station power consumption, pumping station oil flow and number of monitored stations by NERC region. In 2014, the average distance between pumping stations was 135 miles, power consumption was 34,885 megawatt hours per year, and oil flow was $88,000,000$ barrels per year. There are 404 monitored pumping stations.

12. More detail on the STB waybill sample for 2014 is provided in STB (2015).

13. Center for Transportation Analysis, Oak Ridge National Laboratory. (2009). 


\section{RAIL COST PER TON MILE AND PER HOUR FOR IDLING}

To calculate emission costs for rail we rely on four components: 1) gallons of diesel consumed, 2) the EPA locomotive emissions factors, by pollutant, per gallon for 2014, which are based on forecasted fleet composition in 2014, 3) data on movements of crude oil to identify the location of emissions, and 4) the AP3 integrated assessment model, which links emissions to changes in air pollution and changes in air pollution to damages.

\subsection{Diesel Consumed, Emission Factors, and Movements of Crude Oil}

To calculate gallons of diesel consumed, we adopt an approach that distinguishes between outbound (loaded) trains and empty trains returning to North Dakota. ${ }^{14}$ Since trains carrying the weight of crude oil work harder, they consume more fuel and therefore emit more pollution per mile traveled. For outbound trains, we assume that 480 tons of cargo (crude oil) is transported one mile for each gallon of diesel fuel burned by the locomotive. ${ }^{15}$ For return trains, we assume that the empty trains consume 0.37 of the diesel consumed by loaded trains (U.S. Department of State, 2014).

We use EPA (2009) projected locomotive emission rates for 2014, which are based on the forecasted fleet composition of locomotives. The emission rates for nitrogen oxides $\left(\mathrm{NO}_{\mathrm{x}}\right)$, sulfur dioxide $\left(\mathrm{SO}_{2}\right)$, volatile organic compounds (VOCs), fine inhalable particles $\left(\mathrm{PM}_{2.5}\right)$, and carbon dioxide $\left(\mathrm{CO}_{2}\right)$ are expressed in grams per gallon of diesel fuel consumed. Quantities of crude oil shipped from the STB waybill sample are used to calculate the number of barrel-miles for each county along the 41 routes. We convert ton-miles of crude oil transported to gallons of diesel burned in each county. This allows us to compute emissions by county for movements of crude oil from North Dakota in 2014.

One thing to note is that basing fuel consumption on average ton-miles per gallon does not capture the fact that trains are more likely to idle or move at slower speeds in major urban areas. ${ }^{16}$ For example, unit trains take an average of 14 hours to travel through Chicago (CMAP, 2016). Because major junctions occur in urban areas, not accounting for idling and congestion will bias downward our estimates of emissions in urban areas and bias upward estimates of emissions in rural areas. As a result, our aggregate air pollution cost estimates are likely biased downward.

We separately estimate the emissions from trains sitting idle at: Chicago, East St. Louis, and Detroit. The STB reports fuel consumed per hour while idling and switching (STB, 2014). We then combine these estimates of fuel consumption with EPAs gram per gallon emission rates to produce yields estimates of emissions per hour in switching yards. To estimate damages from idling, the emission calculations are coupled with marginal damages, by pollutant, for the counties that contain the three major junctions listed above.

\subsection{AP3 Integrated Assessment Model}

The AP3 integrated assessment model is a new update to the AP2 model (Muller, 2014). Like AP2, AP3 uses an air transport model to link emissions in a specific county to changes in air

14. Our approach is very similar to the approach used in the Environmental Impact Statement (EIS) conducted for the Keystone XL pipeline (United States Department of State, 2014).

15. See United States Department of State (2014), Appendix Y and Association of American Railroads (2017).

16. Similarly, fuel consumption is higher if the grade on the route traveled is positive, so our estimates will understate emissions in counties with positive average grades and overstate them elsewhere. 
pollution in every county in the United States. ${ }^{17}$ It then translates these changes in pollution into estimates of physical impacts by first calculating exposures. This step requires detailed population data provided by the U.S. Census. ${ }^{18}$ Then, using peer-reviewed concentration-response functions, exposures are converted to physical effects including cases of illness and additional deaths. For mortality risk, AP3 uses the concentration-response function for $\mathrm{PM}_{2.5}$ from Krewski et al., (2009), which is widely used by EPA and other researchers.

Most of the monetary damages are due to increased mortality risk and the social cost of carbon. For valuation of mortality risk, AP3 uses the Value of a Statistical Life (VSL) approach. In particular, the AP3 model employs the EPA's VSL estimate of \$8.5 million (2014 U.S. dollars), which is standard in both the academic literature and in policy analyses (EPA, 2011). This VSL is the average of roughly 30 revealed and stated preference studies, each of which estimate a value of statistical life. Importantly, this VSL is applied uniformly across all exposed populations. Finally, $\mathrm{CO}_{2}$ emissions from power plants and locomotives are valued at \$43/ton (2014 U.S. dollars), which is the social cost of carbon estimated by the U.S. government (IWGSCC, 2013).

The AP3 model estimates marginal damages as follows. First, the model calculates the total damage associated with baseline emissions from all sources in 2014 (Muller and Mendelsohn, 2007; 2009). These damages are calculated using emissions, population, and vital statistics from 2014, which is the most recent year for which there are comprehensive emission inventories in the United States. Then, one ton of one pollutant is added to one source. The model re-computes concentrations, exposures, physical effects, and damages with this additional ton of the pollutant. Importantly, the \$/ton damage of pollutant (p) released from location (c) is a spatial sum of impacts over multiple counties that receive pollution (r) from a given source. Note that $D_{r, p, t}^{b}$ reflects the total damage in county (r) from pollutant (p) at time (t) due to the baseline level of emissions, while $D_{r, p, t}^{+1}$ is the total damage when an additional ton of pollutant $(p)$ is added to the baseline emissions.

$$
M D_{p, c, t}=\sum_{r=1}^{R}\left(D_{r, p, t}^{+1}-D_{r, p, t}^{b}\right)
$$

Marginal damages are the difference between the total damages with and without the additional ton of pollutants. Thus, if a locomotive emits a mixture of VOC, $\mathrm{SO}_{2}, \mathrm{PM}_{2.5}$, and $\mathrm{NO}_{\mathrm{x}}$ at ground level in a particular county along a rail route, AP3 accounts for the fact that these emissions disperse into nearby counties.

\section{PIPELINE COSTS PER MEGAWATT}

To calculate emission costs for existing pipelines, we rely on three components: 1) the location and power draws of pumping stations in megawatt hours, 2) the Graff-Zivin, Kotchen, Mansur (2014) model which translates electricity draws into power plant emissions and 3) the AP3 integrated assessment model, which tracks emissions from 600 large power plants and produces unique \$/ton marginal damages for each pollutant emitted from every power plant in the U.S.

17. See Muller (2011) (especially Figure A2 in the supplemental material) and Jaramillo and Muller (2016) (especially the discussion in the appendix on pages 2 and 3) for evidence that the AP2 model correctly predicts monitor-level outcomes.

18. The model calculates damages from human health effects as well as crop and timber yield loss, and materials depreciation. However, the vast majority of impacts are due to human health. 
We use monthly, station-level electricity consumption and pipeline-level crude oil flows from Genscape (2014). ${ }^{19}$ We then employ the method developed by Graff-Zivin, Kotchen, Mansur (2014) to link electricity demand shocks to electricity generation and emission responses. In this method, an electricity demand shock in a given North American Electric Reliability Corporation (NERC) region yields electricity generation responses at many different power plants. Each power plant has a distinct emission rate for each of the pollutants tracked by AP3 (in tons per MWh). We use power plant emissions data from 2010-2012 to estimate emissions rates for each pollutant in each NERC region; this will likely overstate 2014 emissions due to decreases in the percentage of U.S. electricity generation from coal-fired sources. ${ }^{20}$ Emissions of pollutant ( $p$ ) due to pumping station (s), are given by:

$$
E_{p, s}=e_{s} \times \sum_{m=1}^{P} I_{m} f_{p, m}
$$

where $e_{s}$ is the annual electricity consumed by pumping station $s$ (in $\mathrm{MWh}$ ). $I_{m}$ is a $0-1$ indicator function that denotes whether power plant $m$ increases its production in response to the electricity demanded at pumping station $s$. This indicator function varies both at the plant level as well as the NERC region level (based on the location of the pumping station). Finally, $f_{p, m}$ denotes plant $m$ 's emissions rate for pollutant $p$; this pollutant-specific emissions rate varies at the NERC region level. Predicted emission responses by plant are matched to pollutant-and-plant-specific damage estimated by AP3.

\section{AIR POLLUTION AND GREENHOUSE GAS COSTS FOR RAIL AND PIPELINES}

Table 2 presents our estimates of the average air pollution and greenhouse costs per million barrel miles and per gallon for long distance transportation of crude oil from North Dakota to the Gulf Coast in 2014. ${ }^{21}$ Figure 4 plots the relative magnitudes per million barrel miles. ${ }^{22}$ For movements to the Gulf, the sum of air pollution and greenhouse gas costs by rail, $\$ 1,161$, is nearly twice the costs by pipelines, $\$ 676$. Air pollution damages are much larger for rail than for pipeline (\$960 vs. \$427). The greenhouse gas costs are somewhat smaller for rail than for pipelines (\$201 vs. \$249).

Table 2 also reports costs for rail transport to East Coast and West Coast refineries as well as aggregated rail averages for transport of crude out of North Dakota. The air pollution costs per million barrel-miles are the highest for crude oil trains with destinations on the East Coast, $\$ 1,720$, because these trains travel through more densely populated areas. The average air pollution damages are significantly lower for routes to the West Coast, $\$ 618$. This is because trains headed to the West Coast typically do not pass through heavily populated areas such as Chicago or Philadelphia.

19. Genscape monitors electricity consumption at 74 of the 404 pumping stations in our database. For remaining pumping stations, we know location, distance, and flow. We use the electricity demand reported for the monitored pumping stations as well as oil flows to estimate electricity consumption for unmonitored stations on the same pipeline.

20. The United States Department of State (2014), Appendix Y Keystone XL analysis only considers $\mathrm{CO}_{2}$ emissions from power plants because analysis of the emissions of criteria pollutants from power plants was not required for the purposes of the National Environmental Policy Review.

21. Recall that we cannot make similar comparisons for the East Coast and West Coast, because crude oil pipeline capacity to these locations is negligible.

22. For reference, one unit train with 100 cars carries approximately 75,000 barrels. The distance from western North Dakota to either St. James Louisiana or Philadelphia is about 1,970 miles. Moving the equivalent of one train over 1,970 miles is 148 million barrel-miles (75,000 barrels x 1970 miles). 
Table 2: Air Pollution and Greenhouse Gas Damages for Transportation of Crude Oil by Railroad and Pipeline from North Dakota to Refineries

\begin{tabular}{|c|c|c|c|c|c|}
\hline & Pipeline-Gulf & Rail-Gulf Coast & Rail-East Coast & Rail-West Coast & All Rail \\
\hline \multicolumn{6}{|c|}{ (\$) Per million barrel miles } \\
\hline Total & 675.57 & $1,160.57$ & $1,920.82$ & 819.01 & $1,443.39$ \\
\hline Air Pollution & 426.92 & 959.88 & $1,720.13$ & 618.32 & $1,242.70$ \\
\hline Greenhouse Gas & 248.65 & 200.69 & 200.69 & 200.69 & 200.69 \\
\hline \multicolumn{6}{|c|}{ (\$) Per gallon of crude oil } \\
\hline Total & 0.024 & 0.053 & 0.087 & 0.028 & 0.059 \\
\hline Air Pollution & 0.012 & 0.044 & 0.078 & 0.021 & 0.051 \\
\hline Greenhouse Gas & 0.012 & 0.009 & 0.009 & 0.007 & 0.008 \\
\hline
\end{tabular}

\section{Figure 4: Air Pollution and Greenhouse Gas Damages for Transportation by Railroad and} Pipelines to the Gulf Coast

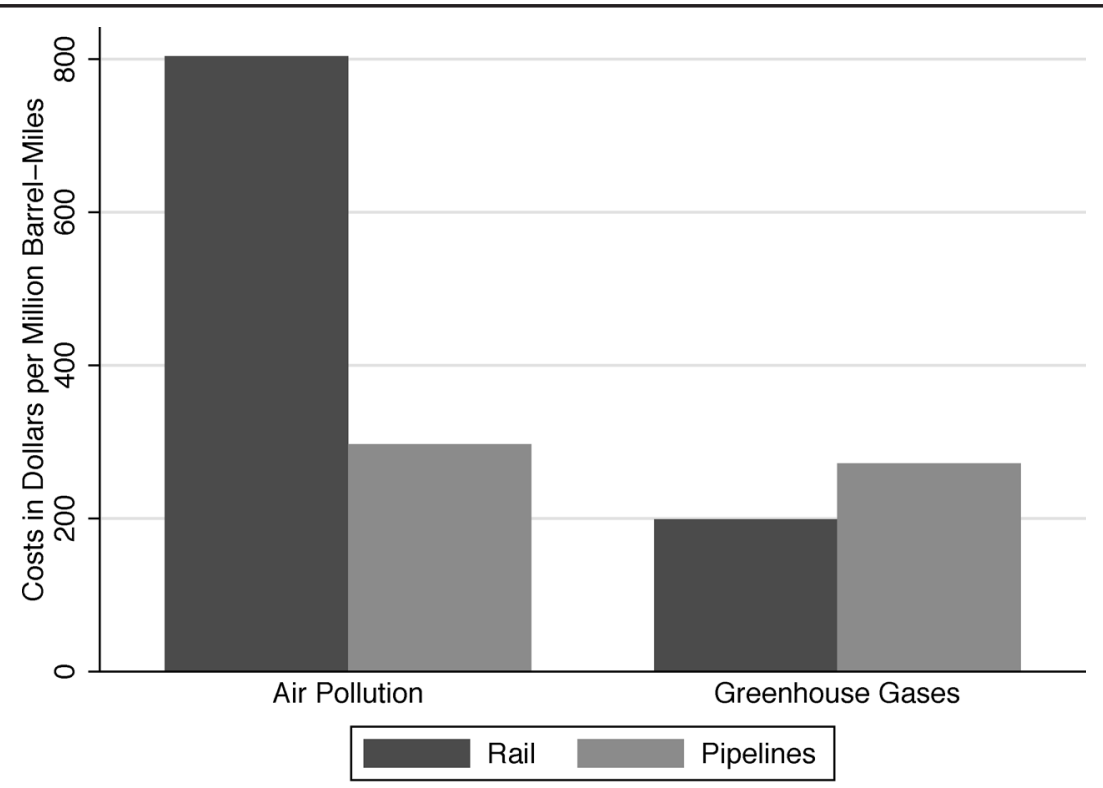

Notes: Data are from the first two columns of the upper panel of Table 2.

Greenhouse gas damages do not vary by location of emission, because greenhouse gases are globally mixed pollutants.

The air pollution and greenhouse gas damages per gallon further differ across regions because the distances traveled varies. The average total damages per gallon of crude oil moved to the Gulf Coast are $\$ 0.024$ for pipelines and $\$ 0.053$ for rail. The average total costs for rail to the East Coast and West Coast are $\$ 0.087$ and $\$ 0.028$, respectively. The route-level average across all routes is $\$ 0.059$ per gallon. ${ }^{23}$

As we noted previously, estimates in Table 2 do not include idling at the origin, destination, or the junctions and so are lower bounds. Appendix Table 1 presents estimates of damages per train hour and per gallon-hour for three major junctions - Chicago, East St. Louis, and Detroit. The costs 
Table 3: Air Pollution and Greenhouse Gas Emissions and Damages by Pollutant

\begin{tabular}{|c|c|c|c|c|}
\hline Pollutant & Pipeline-Gulf Coast & Rail-Gulf Coast & Rail-East Coast & Rail-West Coast \\
\hline \multicolumn{5}{|c|}{ Emissions (tons) per million barrel miles } \\
\hline NO $_{x}$ & 0.005 & 0.061 & 0.061 & 0.061 \\
\hline $\mathrm{SO}_{\mathrm{x}}$ & 0.009 & 0.001 & 0.001 & 0.001 \\
\hline $\mathbf{P M}_{2,5}$ & 0.001 & 0.002 & 0.002 & 0.002 \\
\hline VOC & $*$ & 0.003 & 0.003 & 0.003 \\
\hline $\mathrm{CO}_{2}$ & 5.366 & 4.578 & 4.578 & 4.578 \\
\hline \multicolumn{5}{|c|}{ Damages (\$) per million barrel miles } \\
\hline$\overline{\text { NO }_{x}}$ & 60.93 & 794.15 & $1,341.08$ & 528.28 \\
\hline SO $_{x}$ & 360.84 & 46.08 & 90.72 & 27.39 \\
\hline $\mathbf{P M}_{2.5}$ & 5.15 & 110.58 & 266.48 & 57.91 \\
\hline VOC & $*$ & 9.07 & 21.85 & 4.75 \\
\hline $\mathrm{CO}_{2}$ & 248.65 & 200.69 & 200.69 & 200.69 \\
\hline
\end{tabular}

Figure 5: Air Pollution and Greenhouse Gas Damages for Transportation by Railroad and Pipelines to the Gulf Coast by Pollutant

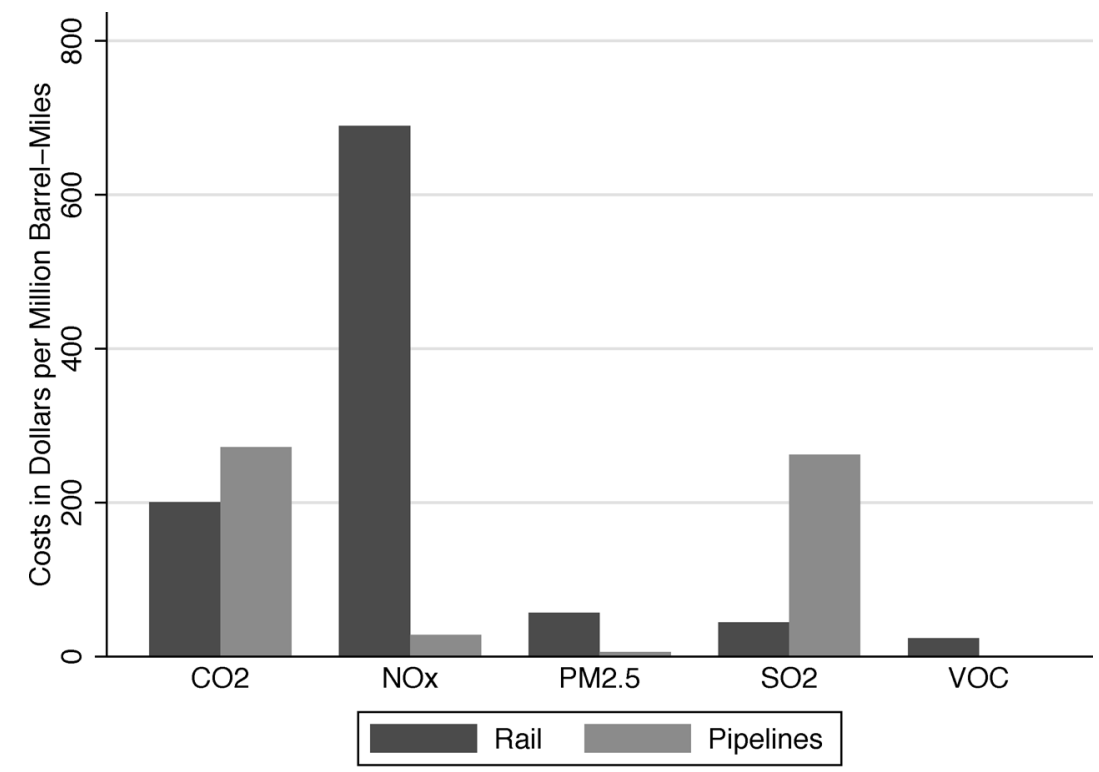

Notes: Data are from the first two columns of the lower panel of Table 3.

on a per hour basis are high, because these are densely populated urban areas, so emissions affect large numbers of individuals. If a train to the East Coast spent one hour idling in Chicago, the air pollution and greenhouse gas costs per gallon would increase from $\$ 0.087$ with no idling to $\$ 0.124$ per gallon with one hour of idling.

Table 3 and Figure 5 present disaggregated pollutant-level comparison of the damages from crude oil transported by rail versus pipeline to the Gulf Coast. It is important to emphasize that the air pollution damages from pipelines are due to emissions in counties with power plants rather than counties with pipelines. The top panel of Table 3 reports emissions per million-barrel-miles, and the bottom panel reports damages. Rail emissions are higher for $\mathrm{NO}_{\mathrm{x}}$ and $\mathrm{PM}_{2.5}$, while pipeline emissions are higher for $\mathrm{SO}_{x}$ and $\mathrm{CO}_{2}$. 
The starkest difference between rail and pipeline is for $\mathrm{NO}_{\mathrm{x}}$. Emissions of $\mathrm{NO}_{\mathrm{x}}$ are 10-times greater for rail than for pipelines, while monetary damages from these $\mathrm{NO}_{\mathrm{x}}$ emissions are 24-times larger for rail relative to pipelines. There are two reasons for this difference in $\mathrm{NO}_{\mathrm{x}}$ emissions and damages. First, trains emit very high levels of $\mathrm{NO}_{\mathrm{x}}$ per million barrel-miles. Second, each ton of pollutant emitted by trains is more harmful than the same ton of pollutant from pipelines, because railroads run through cities. In contrast, pipelines use electricity. Increased electricity generation results in higher emissions from large thermal power plants, which are typically located in rural areas. Thus, population exposures per ton of pollutant are vastly different for rail and pipeline.

How robust are the damage estimates to key modeling assumptions? There are a number of possible sources of error in our calculations including VSL, the social cost of carbon, estimates of power plant emissions, and estimates of the fleet composition of locomotives in 2014.

The model assumed that the VSL was $\$ 8.5$ million (2014 dollars). To explore the importance of this assumption, we re-compute the railroad and pipeline damages using higher $(\$ 12.3$ million) and lower (\$5.2 million) VSLs, relative to our central VSL of \$8.5 million. With our default assumptions, the railroad-to-pipeline damage ratio per million barrel-miles shipped to the Gulf is 1.72. With a lower VSL, the ratio is 1.56 . With a higher-bound VSL, the ratio is 1.84 .

The value of the social cost of carbon was assumed to be $\$ 43 /$ ton. With a lower-bound social cost of carbon of $\$ 7 /$ ton $\mathrm{CO}_{2}$, the railroad-to-pipeline damage ratio (again of moving crude to the Gulf) is 2.09. With a social cost of carbon of $\$ 105 /$ ton $\mathrm{CO}_{2}$, the damage ratio falls to 1.30 .

The Graff-Zivin, Kotchen, Mansur (2014) model is based on 2011 emissions estimates for power generation. Since 2011, relative damages are likely to have changed as electricity generation pollution intensity dropped. Thus, in 2014 there would have likely been an even larger differential between rail and pipeline pollution costs for transportation of crude oil. For example, the eGRID database reports that the power generation fleet emitted 0.62 tons of $\mathrm{CO}_{2} / \mathrm{MWH}$ in 2010. In 2014, $\mathrm{CO}_{2}$ emission intensity is estimated at 0.56 tons/MWH. For $\mathrm{SO}_{2}$ emissions, the emissions rate across all plants was 0.0013 tons/MWH in 2010 whereas in 2014 this rate was 0.0008 tons/MWH. Considering that $\mathrm{CO}_{2}$ and $\mathrm{SO}_{2}$ emissions at power plants comprise the bulk of damages from pipeline transport, it is likely that crude-by-rail is even more harmful, relative to pipelines, today.

To examine the robustness of our results to mis-forecasting of the fleet composition in 2014 by the EPA, we replace the 2014 emission rates with the 2006 and 2030 emission rates for $\mathrm{NO}_{\mathrm{x}}$, $\mathrm{PM}_{2.5}$, and VOC (EPA, 2009) ${ }^{24}$. Using the 2006 locomotive fleet, damages per million-barrel-miles from local air pollution emissions due to rail to the Gulf increase from $\$ 960$ in 2014 to $\$ 1,315$. Conversely, the projected 2030 fleet yields damages of just $\$ 390$; this is incrementally lower than pipeline local air pollution damage in 2014, which is estimated to be $\$ 427$. Of course, in 2030 the electric power grid is likely to be comprised of different fuels than it was in 2014.

Our results generalize to periods before and after 2014 and to other products moved along similar routes. The analysis for 2006 and 2030 in the previous paragraph suggests that our results hold in years before and after 2014. Other products such as ethanol, propane, butane, can be moved by rail and pipeline. The specific characteristics of the product, the pipeline, and the rail route will determine the relative costs, but the wide gap between air pollution and greenhouse gas costs associated with rail and pipeline and the robustness of our findings to changes in modeling assumptions suggests that our findings will apply for these products.

24. We are unable to model emission rates in 2006 and 2030 for $\mathrm{CO}_{2}$ and $\mathrm{SO}_{2}$ as these are a function of fuel consumption rather than abatement technology. As such, we would need to have fleet wide information on fuel economy of locomotives, which are not available for these alternative years. 


\section{SPILL AND ACCIDENT COSTS FOR RAIL AND PIPELINES}

The Pipelines Hazardous Materials Administration (PHMSA) conducted a regulatory impact analysis (RIA) on Enhanced Tank Car Standards and Operational Controls for High-Hazard Flammable Trains in 2015 (PHMSA (2015)). In particular, this RIA developed estimates for crude oil and ethanol of the cost of spills and accidents per carload, which include property damage, cleanup costs, injury costs and mortality costs. PHMSA (2015) presents a range of social costs that can be translated into barrel-miles using information on carloads, barrels per carload, and average distance. ${ }^{25}$ These estimates range from $\$ 214$ per million-barrel miles at the low end to $\$ 966$ per million-barrel miles at the $95^{\text {th }}$ percentile; with a median estimate of $\$ 381$ per million-barrel miles. There is a high level of uncertainty in these estimates, because the probability of a very high cost event, such as a crude oil train explosion near a populated area, is difficult to determine.

PHMSA's (2015) preliminary regulatory impact analysis on pipeline safety contains estimates for 2004-2013 of the cost of spills and accidents for hazardous liquid pipelines, separately for high consequence areas (HCA) and non-high consequence areas (non-HCA). "HL [hazardous liquids] pipelines carry crude oil, refined petroleum products, volatile liquids (such as propane, butane, and ethylene), carbon dioxide, and anhydrous ammonia." ${ }^{26}$ For hazardous liquids, high consequence areas (HCAs) "include populated areas, drinking water sources, and unusually sensitive ecological areas. ${ }^{27}$ Forty-three percent of pipeline miles are in HCA. The annual social costs of spills and accidents per pipeline mile are $\$ 919$ for non-HCA and $\$ 2,392$ for HCA. The estimates include fatalities, injuries, and property damage and are generally considered to be lower bounds of true social costs of spills and accidents due to crude-by-pipeline. ${ }^{28}$ We translate PHMSA's social costs from dollars per mile to dollars per barrel-mile for crude oil, with the caveat that PHMSA's numbers are not calculated separately by product type. ${ }^{29,30}$ The resulting estimate of the cost of spills and accidents per million-barrel miles of crude oil pipeline is roughly $\$ 62$.

The majority of policy concern regarding movements of crude oil by rail and pipeline has focused on the costs associated with accidents and spills. As noted above, PHMSA's central estimates of the costs from spills and accidents for rail and pipelines are $\$ 381$ and $\$ 62$ per million-barrel miles. Firms and insurers pay a share of these costs and the remainder is an externality. However, even if firms did not internalize any of these costs, Figure 6 suggests that the total air pollution and greenhouse gas costs for rail and pipelines to the Gulf Coast are far larger than PHMSA's spills and accidents cost estimates ( $\$ 1,161$ vs. $\$ 381$ for rail; $\$ 676$ vs. $\$ 62$ for pipelines). In sum, policymakers may want to consider the costs from air pollution and greenhouse gases as well as spills and accidents when calculating the social costs of moving crude oil to refineries.

25. PHMSA (2015) Table EB14, p. 111. Carloads are from p. 82 of PHMSA (2015), distance traveled is from p. 200 of PHMSA (2015), and barrels per carload are from Energy Information Administration (2013). Average distance for oil originating in the Bakken is 1,098 miles. The costs are not reported separately for crude oil and ethanol, but the average cost per gallon used in the estimates $(\$ 200)$ is only slightly less than the estimate for crude oil spills, (\$211).

26. Econometrica (2015) p. 15.

27. Econometrica (2015) p. 1.

28. Econometrica (2015) p. 19: "there are important social costs completely missing from the estimates and some costs that are likely underestimates of the true social costs."

29. Econometrica (2015) Appendix A, which lists preventable incidents that occurred during 2010-2014, 12 of the 20 highest cost incidents involved crude oil.

30. Smith, Christopher (2014), appendix. Computing the weighted average cost for the HCA and non-HCA pipelines yields a social cost per pipeline mile for crude oil of $\$ 1,552$. $\$ 62$ per million barrel miles $=(150,609$ miles $x \$ 1552 /$ mile)/3,799,753 million barrel miles. 


\section{Figure 6: Air Pollution and Greenhouse Gas Damages and Spill and Accident Costs for Transportation of Crude Oil by Railroad and Pipelines to the Gulf Coast}

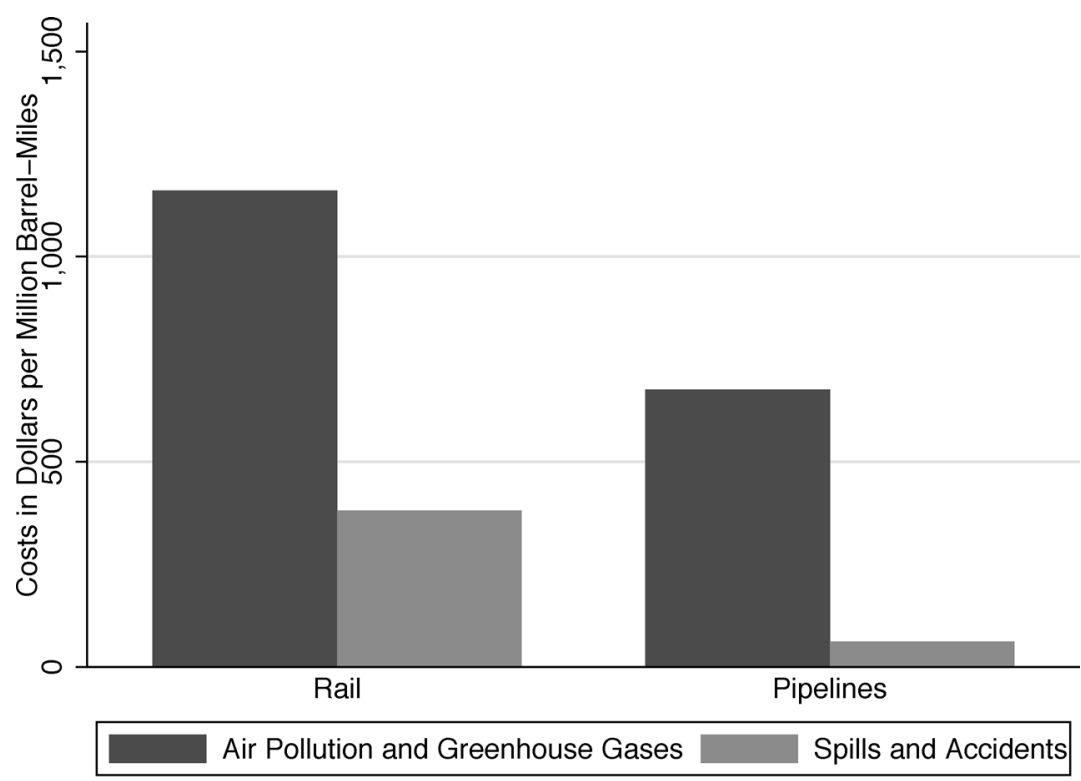

Notes: Data on air pollution and greenhouse gases are from the first two columns of the upper panel of Table 2. Data on spills and accidents are from calculations in the text.

\section{CONCLUSION}

This analysis used data on crude oil transportation from North Dakota in 2014 to examine the relative air pollution, greenhouse gas, and spill and accident costs for movements of petroleum products by rail and pipelines. We find that total air pollution and greenhouse gas costs are substantially larger for rail than for pipelines. The larger costs for rail than pipelines are robust to a variety of modeling assumptions and generalize to other products, routes, and years in North America. Further, for both rail and pipelines, the sum of air pollution and greenhouse gas costs is substantially larger than spill and accidents costs. These results suggest that the policy debate surrounding crude oil transportation has put too much relative weight on accidents and spills. In doing so, a far more serious source of external cost - air pollution and greenhouse gas emissions - has been largely overlooked.

The air pollution and greenhouse gas damages are large. For example, air pollution and greenhouse gas costs of moving a fully loaded 100-car train of crude oil from North Dakota to the Gulf Coast are about $\$ 172,000$ and from North Dakota to the East Coast are \$284,000. The air pollution and greenhouse gas costs of moving an equivalent amount of oil by pipeline to the Gulf Coast are $\$ 100,000$. As we noted, our estimates are a lower bound. This is particularly true for rail because we assume trains do not idle. Idling, particularly in major junction cities such as Chicago, leads to large external pollution costs.

The total estimated damages for oil shipped by rail from North Dakota in 2014 are greater than $\$ 530$ million. According to the National Research Council of the National Academies of Science (NRC), this is more than twice the damage done by the average coal-fired power plant, annually (NRC, 2009). Our analysis suggests that about 50 deaths from air pollution exposure were attributable to shipments of crude by rail in 2014. Crude-by-rail also has additional environmental 
costs due to factors such as the damages from future climate change, increased rates of illness, reduced agricultural and timber production, and accelerated depreciation of man-made materials.

Our work is related to estimates of the pollution attributable to the combustion of gasoline and diesel. The NRC (2009) estimated air pollution damages of between \$0.23/gallon and \$0.38/ gallon, in $\$ 2007$, for 2005 model year autos, trucks, sport utility vehicles, and light trucks burning gasoline. ${ }^{31}$ We report that the external costs associated with transporting one gallon of crude oil to the Gulf Coast averages $\$ 0.053$ for rail and 0.024 for pipelines. Thus, the external costs of long distance transportation of a gallon of crude oil are on the order of one-fifth of the costs of burning a gallon of gasoline or diesel for rail and one-tenth for pipelines. Further, the external costs are about one-fifth of the private cost of shipping for both rail and pipelines. As penetration of pollution control technology in the vehicle fleet continues, damages per gallon will fall. However, population growth puts upward pressure on per-gallon social costs.

The results presented here demonstrate that accounting for the pollution costs of both transporting and burning motor fuels is essential for a life cycle impact analysis of the consumption of these fuels.

\section{REFERENCES}

Association of American Railroads. (2017). The Environmental Benefits of Moving Freight by Rail.

Bushnell, J.B., J.E. Hughes, and A. Smith (2017). "Food vs. Fuel? Impacts of Petroleum Shipments on Agricultural Prices." National Bureau of Economic Research Working Paper \# 23924.

Center for Transportation Analysis, Oak Ridge National Laboratory. (2009). CTA Transportation Networks.

Covert, T.R. and R. Kellogg (2017). “Crude by Rail, Option Value, and Pipeline Investment.” National Bureau of Economic Research Working Paper \# 23855. https://doi.org/10.3386/w23855.

CMAP. (2016). Create Program Status Check. February 20, 2015.

Econometrica. (2015). Preliminary Regulatory Impact Analysis Regulatory Development Support Services Pipeline Safety: Safety of Hazardous Liquid Pipelines Notice of Proposed Rulemaking. Submitted to Pipeline and Hazardous Materials Safety Administration. October.

Energy Information Administration. (2013). Rail delivery of U.S. oil and petroleum products continues to increase, but pace slows. July 10.

Energy Information Administration. (nd). Crude Oil Production, Monthly and Annual.

Energy Information Administration. (nd). Movements of Crude Oil and Selected Products by Rail.

Energy Information Administration. (nd). Refinery Receipts of Crude Oil by Method of Transportation.

Environmental Protection Agency. (2009). Emission Factors for Locomotives. EPA-420-F-09-025 April 2009.

Environmental Protection Agency. (2011). The Benefits and Costs of the Clean Air Act: 1990--2020. Final Report. Office of Air and Radiation, Office of Policy, Washington, D.C.

Forkenbrock, D.J. (2001). "Comparison of the external costs of rail and truck freight transportation." Transportation Research Part A: Policy and Practice 35(4): 321-337. https://doi.org/10.1016/S0965-8564(99)00061-0.

Frittelli, John, et al. (2014). U.S. Rail Transport of Crude Oil: Background and Issues for Congress. R43390. CRS Report for Congress. Washington, DC: Congressional Research Service.

Genscape, Inc. (various dates), PetroRail Report, October 2014 to December 2016.

Genscape, Inc. (2014), MidContinent Pipeline Service Report, data spanning January 2014 to December 2014.

Graff-Zivin, J.S.G., M.J. Kotchen, and E.T. Mansur (2014). "Spatial and temporal heterogeneity of marginal emissions: Implications for electric cars and other electricity-shifting policies." Journal of Economic Behavior \& Organization 107: 248-268. https://doi.org/10.1016/j.jebo.2014.03.010.

Haling, D. and H. Cohen (1995). Air quality cost analysis spreadsheet. Data provided by the authors. Cambridge Systematics. Inc, Washington, DC.

Jaramillo, P. and N.Z. Muller (2016). "Air pollution emissions and damages from energy production in the U.S.: 2002-2011." Energy Policy 90: 202-211. https://doi.org/10.1016/j.enpol.2015.12.035.

31. See NRC (2009), p. 11 footnote 10. For light-duty vehicles from the late 1990s, Parry, Walls, and Harrington (2007) estimates air pollution damages of $\$ 0.52 /$ gallon.

All rights reserved. Copyright (C) 2019 by the IAEE. 
Krewski, D., M. Jerrett, R.T. Burnett, R. Ma, E. Hughes, Y. Shi, et al. (2009). Extended follow-up and spatial analysis of the American Cancer Society study linking particulate air pollution and mortality. HEI Research Report, 140, Health Effects Institute, Boston, MA.

Muller, N.Z. (2011). "Linking policy to statistical uncertainty in air pollution damages." The BE Journal of Economic Analysis \& Policy 11(1): 1-29. https://doi.org/10.2202/1935-1682.2925.

Muller, N.Z. (2014). "Boosting GDP growth by accounting for the environment: Including air pollution and greenhouse gas damages increases estimated U.S. growth.” Science 345(6199): 873-874. https://doi.org/10.1126/science.1253506.

Muller, N. Z. and R. Mendelsohn (2007). "Measuring the damages of air pollution in the United States." Journal of Environmental Economics and Management 54(1): 1-14. https://doi.org/10.1016/j.jeem.2006.12.002.

Muller, N.Z. and R. Mendelsohn (2009). "Efficient pollution regulation: getting the prices right." American Economic Review 99(5): 1714-39. https://doi.org/10.1257/aer.99.5.1714.

National Academies of Science, National Research Council (NRC). (2009). Hidden Costs of Energy: Un-priced Consequences of Energy Production and Use. The National Academies Press, Washington DC, USA.

National Economic Research Associates (NERA). (1993). External costs of electric utility resource selection in Nevada. Final report, Prepared for the Nevada Power Company, Cambridge, MA.

North Dakota Pipeline Authority. (2015). Crude Oil Gathering In North Dakota, November 10.

Parry, I.W.H., M. Walls, and W. Harrington (2007). “Automobile Externalities and Policies.” Journal of Economic Literature 45(2): 373-399. https://doi.org/10.1257/jel.45.2.373.

Pipeline and Hazardous Materials Safety Administration (2015). Final Regulatory Impact Analysis [Docket No. PHMSA-2012-0082] (HM-251) Hazardous Materials: Enhanced Tank Car Standards and Operational Controls for High-Hazard Flammable Trains; Final Rule. Office of Hazardous Material Safety, May.

Smith, C.E. (2014). "Crude oil pipeline growth, revenues surge; construction costs mount.” Oil \& Gas Journal 112(9): 114125.

Smith, M. (2017). "With Big Spill to Clean, Pipeline Owner Seeks Keystone XL Approval.” New York Times November 17, 2017.

Surface Transportation Board. (2014). EP 724 - Rail Service Issues Reports.

Surface Transportation Board. (2015). 2014 Surface Transportation Board Carload Waybill Sample Reference Guide, November 1, 2015.

United States Department of Agriculture. (2015). Rail Service Challenges in the Upper Midwest: Implications for Agricultural Sectors-Preliminary Analysis of the 2013-2014 Situation.

United States Department of State. (2014). Final Supplemental Environmental Impact Statement for the KEYSTONE XL PROJECT.

U.S. Interagency Working Group on Social Cost of Carbon (IWGSCC). (2013). Technical Update of the Social Cost of Carbon for Regulatory Impact Analysis Under Executive Order 12866 (November 2013) 


\section{APPENDIX}

The equation for the estimation of the emission rates in tons per county is given by the following formula in which county is denoted (c) and pollutant (p):

$$
\begin{aligned}
E_{p, c}= & D_{c}\left(\frac{\text { miles }}{\text { county }}\right) \times 0.14259\left(\frac{\text { tons }}{\text { bbl. }}\right) \times\left(\frac{\text { bbl. }}{\text { train }}\right) \times\left(480 \frac{\text { ton }- \text { miles. } .}{\text { gal }}\right)^{-1} \\
& \times E_{p}\left(\frac{\text { grams }}{\text { gal. }}\right) \times\left(\frac{\text { tons }}{9.07 \times 10^{5} \text { grams }}\right)
\end{aligned}
$$

We estimate damages by county because the (\$/ton) marginal damages are calculated by AP2 at the county level. Damages are then aggregated across all counties with a route. Finally, we divide damages by barrel-miles, by route, and scale up by 1,000,000 to compute damages per million barrel-miles.

\section{Appendix Table 1: Air Pollution and Greenhouse Gas Damages from Idling by Pollutant and}

\begin{tabular}{|c|c|c|c|c|}
\hline Pollutant & Chicago & East St. Louis & Detroit & All Junctions \\
\hline \multicolumn{5}{|c|}{ Damages (\$) per train-hour } \\
\hline All & $2,419.79$ & 713.37 & $1,486.16$ & $1,990.85$ \\
\hline NO $_{x}$ & $1,804.85$ & 508.66 & $1,057.92$ & $1,478.12$ \\
\hline $\mathrm{SO}_{\mathrm{x}}$ & 60.61 & 19.72 & 42.04 & 50.43 \\
\hline $\mathbf{P M}_{2.5}$ & 440.56 & 99.22 & 285.18 & 355.52 \\
\hline VOC & 36.13 & 8.12 & 23.38 & 29.15 \\
\hline $\mathrm{CO}_{2}$ & 77.64 & 77.64 & 77.64 & 77.64 \\
\hline \multicolumn{5}{|c|}{ Damages (\$) per barrel-hour } \\
\hline All & 0.0371 & 0.0098 & 0.0151 & 0.0303 \\
\hline NO $_{x}$ & 0.0277 & 0.0070 & 0.0100 & 0.0225 \\
\hline SO $_{x}$ & 0.0009 & 0.0003 & 0.0005 & 0.0008 \\
\hline $\mathbf{P M}_{2.5}$ & 0.0068 & 0.0014 & 0.0023 & 0.0054 \\
\hline VOC & 0.0006 & 0.0001 & 0.0010 & 0.0004 \\
\hline $\mathrm{CO}_{2}$ & 0.0012 & 0.0011 & 0.0013 & 0.0012 \\
\hline
\end{tabular}
Junction 